\title{
A New Power System Phase Identification Method based on Difference Value
}

\author{
Liu Bo ${ }^{1, ~ a ~}$, Chen Bo-neng ${ }^{2, b}$, Li Jie ${ }^{3, b}$, Xia Rui-hua ${ }^{1, b}$ \\ ${ }^{1}$ North China Electric Power University, Beijing, 102206, China \\ ${ }^{2}$ State Grid Chongqing Electric Power Company, Chongqing, 400000, China \\ ${ }^{3}$ State Grid Tianjin Electric Power Company, Tianjin, 300232, China \\ aemail: 812513178@qq.com, bemail: Ib200411@sina.com
}

Keywords: Power System; Phase Identification; Difference Value; Generalized Admittance

\begin{abstract}
In accordance with the problems of phase selection method based on difference of phase-to-phase current, that is, phase selection mistake when double-phase ground fault occur and insufficient sensitivity of phase selection when the positive and negative sequence impedances of system are not equal, a new power system phase identification method based on difference value was proposed. The method combined difference of phase voltages with difference of phase-to-phase current, and three generalized admittances were defined to identify phases by comparing their values. The simulation results showed that this method could identify phases correctly on different fault location and different fault resistance, it has sufficient sensitivity and high reliability.
\end{abstract}

\section{Introduction}

Phase identification based on difference value is one of phase identification methods adopted by digital high voltage line protection [1,2]. It is based on the voltage and current before and after fault to calculate the corresponding fault component, and to classify faults by analyzing their amplitude characteristics [3]. Now, the kind of method included difference of phase-to-phase current method based on $\Delta I_{\Phi \Phi}$, difference of phase-to-phase current method based on $\Delta U_{\Phi \Phi}$, combined Method based on $\Delta U_{\Phi \Phi}+K \Delta I_{\Phi \Phi}$ [4,5]. The method based on difference of phase-to-phase current is widely used, but it has problems [6], such as phase identification mistake when double phase-grounded fault accompanied by the situation that positive sequence impedance is greatly larger than zero sequence impedance of system and insufficient sensitivity of phase selection when the positive and negative sequence impedances of system are not equal. A new power system phase identification method based on difference value was proposed to solve this two problems.

\section{Fault Characteristics Analysis}

Taking the dual power supply system showed in Figure 1 as a example to analyze characteristics of faults.

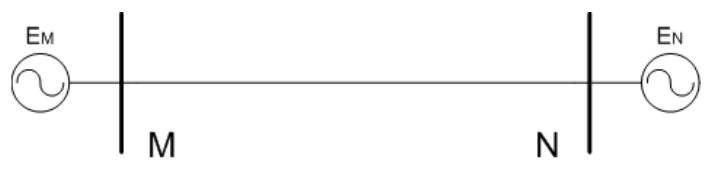

\section{Single-phase ground fault}

Fig.1. The dual power supply system

Taking phase A ground fault as a example, when the positive and negative sequence current distribution coefficient are equal at relay location, the differences of phase-to-phase current are calculated as follows. 


$$
\begin{aligned}
& \left|\Delta I_{A B}\right|=3\left|C_{1} I_{1}\right| \\
& \left|\Delta I_{B C}\right|=0 \\
& \left|\Delta I_{A C}\right|=3\left|C_{1} I_{1}\right|
\end{aligned}
$$

It shows that there are $\left|\Delta I_{B C}\right|<\left|\Delta I_{A C}\right|$ and $\left|\Delta I_{B C}\right|<\left|\Delta I_{A B}\right|$ in this case.

The differences of phase voltage are calculated as follows.

$$
\begin{aligned}
\Delta U_{A} & =\frac{2 C_{1} Z_{S 1}+C_{0} Z_{S 0}}{2 Z_{1}+Z_{0}+3 Z_{g}} U_{k A} \\
\Delta U_{B} & =\frac{C_{0} Z_{S 0}-C_{1} Z_{S 1}}{2 Z_{1}+Z_{0}+3 Z_{g}} U_{k A} \\
\Delta U_{C} & =\frac{C_{0} Z_{S 0}-C_{1} Z_{S 1}}{2 Z_{1}+Z_{0}+3 Z_{g}} U_{k A}
\end{aligned}
$$

According to the voltage phasor diagram [6], there are usually $\left|\Delta U_{A}\right|>\left|\Delta U_{B}\right|$ and $\left|\Delta U_{A}\right|>\left|\Delta U_{C}\right|$.

\section{Double-phase short circuit fault}

Taking phase $\mathrm{B}$ and $\mathrm{C}$ short circuit fault as a example, the differences of phase-to-phase current are calculated as follows.

$$
\begin{aligned}
& \left|\Delta I_{A B}\right|=\sqrt{3}\left|C_{1} I_{1}\right| \\
& \left|\Delta I_{B C}\right|=2 \sqrt{3}\left|C_{1} I_{1}\right| \\
& \left|\Delta I_{A C}\right|=\sqrt{3}\left|C_{1} I_{1}\right|
\end{aligned}
$$

It shows that there are $\left|\Delta I_{B C}\right|>\left|\Delta I_{A C}\right|$ and $\left|\Delta I_{B C}\right|>\left|\Delta I_{A B}\right|$ in this case.

The differences of phase voltage are calculated as follows.

$$
\begin{aligned}
\Delta U_{A} & =\frac{2 Z_{2}+\left(C_{1} Z_{M 1}-C_{2} Z_{M 2}\right)\left(Z_{1}+Z_{2}\right)}{2 Z_{2}} \stackrel{\square}{U A}^{\square} \\
\Delta U_{B} & =\frac{\alpha^{2}\left(Z_{2}+C_{1} Z_{M 1}\right)+\alpha\left(Z_{2}-C_{2} Z_{M 2}\right)}{2 Z_{2}} \stackrel{\square}{U A}_{k A} \\
\Delta U_{C} & =\frac{\alpha\left(Z_{2}+C_{1} Z_{M 1}\right)+\alpha^{2}\left(Z_{2}-C_{2} Z_{M 2}\right)}{2 Z_{2}} U_{k A}
\end{aligned}
$$

According to the voltage phasor diagram [6], there are usually $\left|\Delta U_{A}\right|<\left|\Delta U_{B}\right|$ and $\left|\Delta U_{A}\right|<\left|\Delta U_{C}\right|$.

\section{Three-phase short circuit fault}

When Three-phase short circuit fault occurs, the differences of phase-to-phase current are calculated as follows.

$$
\left|\Delta I_{A B}\right|=\left|\Delta I_{B C}\right|=\left|\Delta I_{A C}\right|
$$

It shows that there are $\left|\Delta I_{B C}\right|=\left|\Delta I_{A C}\right|=\left|\Delta I_{A B}\right|$.

The differences of phase voltage are calculated as follows.

$$
\begin{aligned}
\Delta U_{A} & =\frac{C_{1} Z_{M 1}}{Z_{1}+Z_{g}} U_{k A} \\
\Delta U_{B} & =\alpha \frac{C_{1} Z_{M 1}}{Z_{1}+Z_{g}} U_{k A} \\
\Delta U_{C} & =\alpha \frac{C_{1} Z_{M 1}}{Z_{1}+Z_{g}} U_{k A}
\end{aligned}
$$

According to the voltage phasor diagram [6], there are usually $\left|\Delta U_{A}\right|=\left|\Delta U_{B}\right|=\left|\Delta U_{C}\right|$. 


\section{Double-phase ground fault}

Taking phase $\mathrm{B}$ and $\mathrm{C}$ ground fault as a example, the differences of phase-to-phase current are calculated as follows $(0<k<1)$.

$$
\begin{aligned}
& \left|\Delta I_{A B}\right|=\sqrt{3}\left|C_{1}(1-k+\alpha) I_{1}\right| \\
& \left|\Delta I_{B C}\right|=\sqrt{3}\left|C_{1}(1+k) I_{1}\right| \\
& \left|\Delta I_{A C}\right|=\sqrt{3}\left|C_{1}(1-k-\alpha k) I_{1}\right|
\end{aligned}
$$

It shows that there are $\left|\Delta I_{B C}\right|>\left|\Delta I_{A C}\right|$ 且 $\left|\Delta I_{B C}\right|>\left|\Delta I_{A B}\right|$;

The differences of phase voltage are calculated as follows.

$$
\begin{aligned}
\Delta U_{A}= & \left(1+\frac{\left(Z_{2}+Z_{0}\right)\left[C_{1} Z_{M 1}\left(Z_{2}+Z_{0}+3 Z_{g}\right)-C_{2} Z_{M 2}\left(Z_{0}+3 Z_{g}\right)-C_{0} Z_{M 0} Z_{2}\right]}{3 Z_{2}\left(Z_{0}+3 Z_{g}\right)\left(Z_{2}+Z_{0}+3 Z_{g}\right)}\right) U_{k A} \\
& \alpha^{2}\left[Z_{2}\left(Z_{0}+3 Z_{g}\right)+C_{1} Z_{M 1}\left(Z_{2}+Z_{0}+3 Z_{g}\right)\right] \\
\Delta U_{B}= & \frac{+\alpha\left(Z_{2}-C_{2} Z_{M 2}\right)\left(Z_{0}+3 Z_{g}\right)-Z_{2}\left(C_{0} Z_{M 0}-Z_{0}-3 Z_{g}\right)}{3 Z_{2}\left(Z_{0}+3 Z_{g}\right)} U_{k A} \\
& \alpha\left[Z_{2}\left(Z_{0}+3 Z_{g}\right)+C_{1} Z_{M 1}\left(Z_{2}+Z_{0}+3 Z_{g}\right)\right] \\
\Delta U_{C}= & \frac{+\alpha^{2}\left(Z_{2}-C_{2} Z_{M 2}\right)\left(Z_{0}+3 Z_{g}\right)-Z_{2}\left(C_{0} Z_{M 0}-Z_{0}-3 Z_{g}\right)}{3 Z_{2}\left(Z_{0}+3 Z_{g}\right)} U_{k A}
\end{aligned}
$$

According to the voltage phasor diagram [6], there are usually $\left|\Delta U_{A}\right|<\left|\Delta U_{B}\right|$ and $\left|\Delta U_{A}\right|<\left|\Delta U_{C}\right|$.

In Eq. 1 to Eq. 8, $Z_{s 1} 、 Z_{s 0}$ are positive sequence and zero sequence impedances of the power supply respectively. $Z_{M 1} 、 Z_{M 2} 、 Z_{M 0}$ are positive, negative and zero sequence impedances from relay to the fault point respectively. $U_{k A}$ is fault voltage of phase $\mathrm{A}, Z_{g}$ is fault resistance. $Z_{1} 、 Z_{2} 、 Z_{0}$ are equivalent impedances of positive, negative and zero sequence network to the fault point respectively. $C_{1} 、 C_{2} 、 C_{0}$ are distribution coefficients of positive, negative and zero sequence current respectively.

\section{The New Phase Identification Method}

Generalized admittance is defined as follows.

$$
Y_{\phi 1}=\left|\frac{\Delta I_{\phi 2 \phi 3}}{\Delta U_{\phi 1}}\right|
$$

In Eq. 9, $\Phi_{1} 、 \Phi_{2} 、 \Phi_{3}$ represent three phases. Then,

$$
Y_{A}=\left|\frac{\Delta I_{B C}}{\Delta U_{A}}\right|, Y_{B}=\left|\frac{\Delta I_{A C}}{\Delta U_{B}}\right|, Y_{C}=\left|\frac{\Delta I_{A B}}{\Delta U_{C}}\right|
$$

Based on the above analysis, comparing the sizes of $Y_{\mathrm{A}}, Y_{\mathrm{B}}, Y_{\mathrm{C}}$, the results are showed in Table 1.

Table 1 The sizes of $Y_{\mathrm{A}}, Y_{\mathrm{B}}, Y_{\mathrm{C}}$

\begin{tabular}{|l|l|l|l|}
\hline Type of faults & $Y_{\mathrm{A}}$ & $Y_{\mathrm{B}}$ & $Y_{\mathrm{C}}$ \\
\hline AG & small & large & large \\
\hline BC、 BCG & large & small & small \\
\hline ABC & equal & \\
\hline
\end{tabular}

The fault criterions are defined as follows. Formula (11) is the criterion 1, formula (12) is the criterion 2, $m$ is restrained coefficient. 
$\left\{\begin{array}{l}m Y_{\phi 1}<Y_{\phi 2} \\ m Y_{\phi 1}<Y_{\phi 3}\end{array}\right.$
$\left\{\begin{array}{l}Y_{\phi 1}>m Y_{\phi 2} \\ Y_{\phi 1}>m Y_{\phi 3}\end{array}\right.$

The phase selection process is showed in Figure 2.

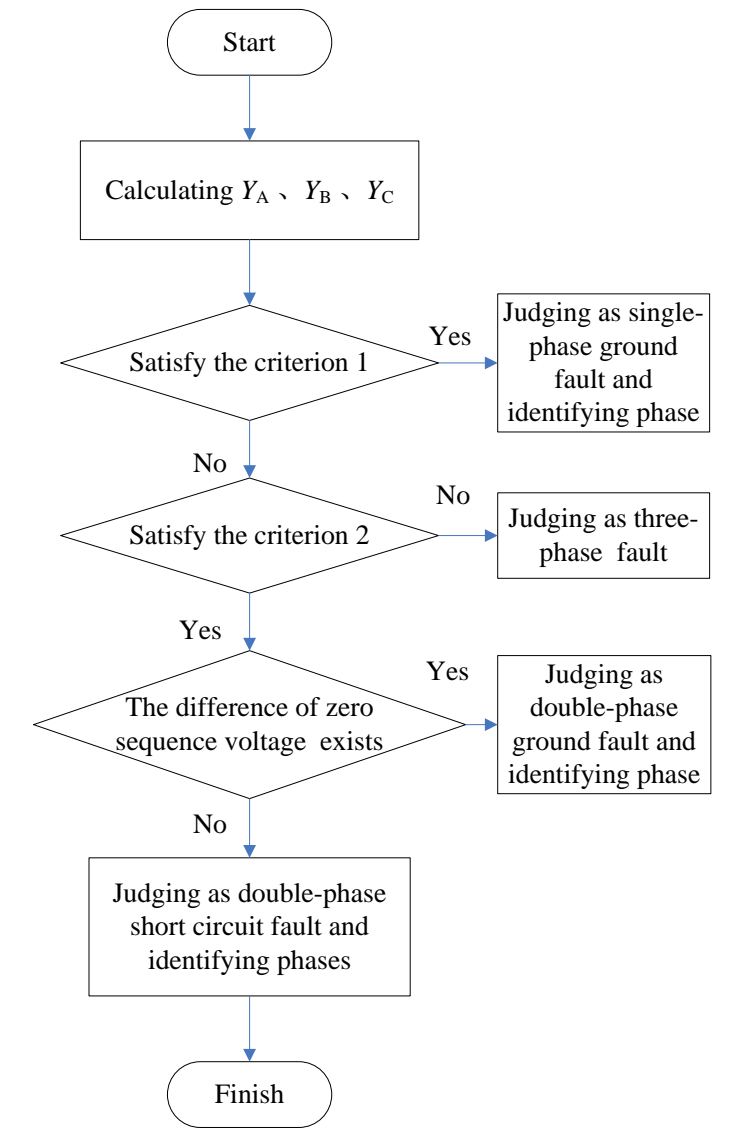

Fig.2. The phase selection process

Double-phase short circuit fault and Double-phase ground fault both satisfy the criterion 2, therefore the difference of zero sequence voltage is employed to distinguish them. The restrained coefficient $m$ set as 4 .

\section{Simulation results}

The ATP-EMTP was employed in the simulation. The relay was set at $\mathrm{M}$ side. In the model, the line which is $300 \mathrm{~km}$ has single-loop and double-side power supply, the voltage level was $500 \mathrm{kV}$. The simulation parameters set as follows.

$$
\begin{aligned}
& U_{\mathrm{M}}{ }^{*}=1.00 \angle 0^{\circ}, U_{\mathrm{N}}{ }^{*}=1.05 \angle-25^{\circ} . \\
& R_{1}=0.02783 \Omega / \mathrm{km}, L_{1}=0.8863 \mathrm{mH} / \mathrm{km}, C_{1}=0.0127 \mu \mathrm{F} / \mathrm{km} . \\
& R_{0}=0.1948 \Omega / \mathrm{km}, L_{0}=2.0682 \mathrm{mH} / \mathrm{km}, C_{0}=0.009 \mu \mathrm{F} / \mathrm{km} .
\end{aligned}
$$

Situations of $Z_{0}<<Z_{1}$

In this situation, setting $Z_{\mathrm{MS} 1}=4.534+\mathrm{j} 65.9 \Omega, Z_{\mathrm{MS} 0}=1.221+\mathrm{j} 6.59 \Omega, Z_{\mathrm{NS} 1}=2.534+\mathrm{j} 20.46 \Omega$, $Z_{\mathrm{NS} 0}=1.121+\mathrm{j} 6.723 \Omega$. Setting the fault point at $\mathrm{M}$ side, $50 \%$ of line and $\mathrm{N}$ side respectively, and fault resistance is $0 \Omega$ or $300 \Omega$. The simulation results are shown in Table 2 and Table 3.

\section{Situations of $Z_{1} \neq Z_{2}$}

In the simulation model, the power system of $\mathrm{M}$ side is replaced by a generator. The values of positive and negative sequence impedances of system are changed by setting the values of direct-axis sub-transient reactance $X_{\mathrm{d}}$ " and quadrature-axis sub-transient reactance $X_{\mathrm{q}}$ " respectively. 
In this situation, setting $X_{\mathrm{d}}=4.14, X_{\mathrm{d}}{ }^{\prime}=0.314, X_{\mathrm{d}}$ " $=0.18, X_{\mathrm{q}}=2.7, X_{\mathrm{q}}{ }^{\prime \prime}=0.2, Z_{\mathrm{NS} 1}=2.534+\mathrm{j} 20.46 \Omega$, $Z_{\mathrm{NS} 0}=1.121+\mathrm{j} 6.723 \Omega$. Adjusting the generator capacity to set the rated current $I_{\mathrm{N}}=1.17 \mathrm{kA}$.

The simulation results are shown in Table 4 and Table 5.

Table 2 The results of simulation which fault resistance is $0 \Omega$ in situations of $Z_{0}<<Z_{1}$

\begin{tabular}{|l|l|l|l|l|}
\hline \multicolumn{2}{|l|}{ The fault types } & AG & BCG & ABC \\
\hline \multirow{4}{*}{ Fault at M side } & $Y_{\mathrm{A}}$ & 0.62 & 1262.00 & 35.85 \\
\cline { 2 - 5 } & $Y_{\mathrm{B}}$ & 171.72 & 13.62 & 28.44 \\
\cline { 2 - 5 } & $Y_{\mathrm{C}}$ & 231.68 & 17.92 & 25.15 \\
\hline \multirow{3}{*}{$\begin{array}{l}\text { Fault at 50\% of } \\
\text { line }\end{array}$} & $Y_{\mathrm{A}}$ & 0.69 & 708.75 & 53.00 \\
\cline { 2 - 5 } & $Y_{\mathrm{B}}$ & 209.89 & 12.23 & 55.87 \\
\cline { 2 - 5 } & $Y_{\mathrm{C}}$ & 139.00 & 36.33 & 52.98 \\
\hline \multirow{3}{*}{ Fault at N side } & $Y_{\mathrm{A}}$ & 0.06 & 446.75 & 62.68 \\
\cline { 2 - 5 } & $Y_{\mathrm{B}}$ & 419.00 & 5.48 & 64.71 \\
\cline { 2 - 5 } & $Y_{\mathrm{C}}$ & 50.25 & 37.81 & 68.11 \\
\hline Recognition results & $\mathrm{AG}$ & $\mathrm{BCG}$ & $\mathrm{ABC}$ \\
\hline
\end{tabular}

Table 3 The results of simulation which fault resistance is $300 \Omega$ in situations of $Z_{0}<<Z_{1}$

\begin{tabular}{|l|l|l|l|l|}
\hline \multicolumn{2}{|l|}{ The fault types } & AG & BCG & ABC \\
\hline \multirow{4}{*}{ Fault at M side } & $Y_{\mathrm{A}}$ & 0.86 & 1479.43 & 35.86 \\
\cline { 2 - 5 } & $Y_{\mathrm{B}}$ & 131.67 & 25.55 & 28.93 \\
\cline { 2 - 5 } & $Y_{\mathrm{C}}$ & 24.76 & 41.14 & 25.65 \\
\hline \multirow{3}{*}{$\begin{array}{l}\text { Fault at } \text { line } \\
\text { Fault at N side }\end{array}$} & $Y_{\mathrm{A}}$ & 0.39 & 1087.60 & 51.56 \\
\cline { 2 - 5 } & $Y_{\mathrm{B}}$ & 210.11 & 11.81 & 56.98 \\
\cline { 2 - 5 } & $Y_{\mathrm{C}}$ & 26.19 & 36.84 & 54.65 \\
\cline { 2 - 5 } & $Y_{\mathrm{A}}$ & 1.72 & 397.11 & 63.24 \\
\cline { 2 - 5 } & $Y_{\mathrm{B}}$ & 18.29 & 5.41 & 64.95 \\
\cline { 2 - 5 } & $Y_{\mathrm{C}}$ & 11.25 & 36.90 & 68.28 \\
\hline \multicolumn{2}{|l|}{ Recognition results } & $\mathrm{AG}$ & $\mathrm{BCG}$ & $\mathrm{ABC}$ \\
\hline
\end{tabular}

Table 4 The results of simulation which fault resistance is $0 \Omega$ in situations of $Z_{1} \neq Z_{2}$

\begin{tabular}{|l|l|l|l|l|}
\hline \multicolumn{2}{|l|}{ The fault types } & AG & BCG & ABC \\
\hline \multirow{4}{*}{ Fault at M side } & $Y_{\mathrm{A}}$ & 0.17 & 35.57 & 6.34 \\
\cline { 2 - 5 } & $Y_{\mathrm{B}}$ & 26.91 & 2.24 & 6.41 \\
\cline { 2 - 5 } & $Y_{\mathrm{C}}$ & 13.67 & 3.62 & 6.50 \\
\hline \multirow{3}{*}{$\begin{array}{l}\text { Fault at 50\% of } \\
\text { line }\end{array}$} & $Y_{\mathrm{A}}$ & 0.29 & 67.21 & 21.43 \\
\cline { 2 - 5 } & $Y_{\mathrm{B}}$ & 178.80 & 2.41 & 21.48 \\
\cline { 2 - 5 } & $Y_{\mathrm{C}}$ & 15.58 & 5.84 & 22.69 \\
\hline \multirow{3}{*}{ Fault at N side } & $Y_{\mathrm{A}}$ & 0.44 & 55.08 & 87.53 \\
\cline { 2 - 5 } & $Y_{\mathrm{B}}$ & 63.20 & 5.74 & 87.60 \\
\cline { 2 - 5 } & $Y_{\mathrm{C}}$ & 10.00 & 12.32 & 88.62 \\
\hline Recognition results & $\mathrm{AG}$ & $\mathrm{BCG}$ & $\mathrm{ABC}$ \\
\hline
\end{tabular}

Table 5 The results of simulation which fault resistance is $300 \Omega$ in situations of $Z_{1} \neq Z_{2}$

\begin{tabular}{|l|l|l|l|l|}
\hline \multicolumn{2}{|l|}{ The fault types } & $\mathrm{AG}$ & $\mathrm{BCG}$ & $\mathrm{ABC}$ \\
\hline \multirow{4}{*}{ Fault at M side } & $Y_{\mathrm{A}}$ & 0.23 & 125.31 & 6.86 \\
\cline { 2 - 5 } & $Y_{\mathrm{B}}$ & 11.86 & 2.28 & 6.51 \\
\cline { 2 - 5 } & $Y_{\mathrm{C}}$ & 53.51 & 5.63 & 7.29 \\
\hline \multirow{3}{*}{$\begin{array}{l}\text { Fault at 50\% of } \\
\text { line }\end{array}$} & $Y_{\mathrm{A}}$ & 0.23 & 231.7 & 23.34 \\
\cline { 2 - 5 } & $Y_{\mathrm{B}}$ & 30.25 & 0.03 & 22.69 \\
\cline { 2 - 5 } & $Y_{\mathrm{C}}$ & 43.05 & 18.51 & 23.76 \\
\hline \multirow{3}{*}{ Fault at N side } & $Y_{\mathrm{A}}$ & 0.36 & 1137.50 & 88.49 \\
\cline { 2 - 5 } & $Y_{\mathrm{B}}$ & 15.33 & 1.24 & 88.93 \\
\cline { 2 - 5 } & $Y_{\mathrm{C}}$ & 69.71 & 88.74 \\
\hline Recognition results & 588.00 & $\mathrm{BCG}$ & $\mathrm{ABC}$ \\
\hline
\end{tabular}

\section{Results analysis}

According to the simulation results, the new phase identification method based on difference value has good performance and sufficient sensitivity of phase selection in the situations that positive sequence impedance is greatly larger than zero sequence impedance of system $\left(Z_{0}<<Z_{1}\right)$ and the positive and negative sequence impedances of system are not equal $\left(Z_{1} \neq Z_{2}\right)$. In addition, the 
value of restrained coefficient is reasonable.

\section{Conclusions}

In the paper, a new power system phase identification method based on difference value was proposed. The method combined difference of phase voltages with difference of phase-to-phase current, and three generalized admittances were defined to identify phases by comparing their values. The simulation results showed that this method could identify phases correctly in the situations where system parameters are $Z_{0}<<Z_{1}$ and $Z_{1} \neq Z_{2}$. The validity of the method would not be affected by different fault locations and different fault resistances, it had sufficient sensitivity and high reliability.

\section{References}

[1] Thompson Adu. An Accurate Fault Classification Technique for Power System Monitoring Devices [J]. IEEE Trans on Power Delivery,2002,17(3):684-690.

[2] Gabriel Benmouyal, Jean Mahseredjian. A Combined Directional and Faulted Phase Selection Element based on Incremencal Quantities [J]. IEEE Trans on Power Delivery,2001,16(4):478-484.

[3] MA Jing, WANG Xi, WANG Zeng-ping. A New Fault Phase Identification Method Based on Phase Current Difference [J]. Proceedings of the CSEE. 2012, 32(19) :117-124 (in Chinese).

[4] Lu Wen-jun, Lin Xiang-ning, et al. A Novel Adaptive Phase Selector Based On Fault Component [J]. Proceedings of the CSEE. 2007, 27(28):53-58 (in Chinese).

[5] Duan Jian-dong, Zhang Bao-hui, Zhou Yi, et al. Transient- based Faulty Phase Selection in EHV Transmission Lines [J]. Proceedings of the CSEE, 2006, 26(3):1-6(in Chinese).

[6] GE Yao-zhong. A New Type of Relay Protection and Fault Location Principle and Technology [M]. Xi'an: Xi'an Jiaotong University Press, 1996 (in Chinese). 